\title{
The effects of injecting intra-articular platelet- rich plasma or prolotherapy on pain score and function in knee osteoarthritis
}

This article was published in the following Dove Press journal:

Clinical Interventions in Aging

\author{
Poupak Rahimzadeh' \\ Farnad Imani' \\ Seyed Hamid Reza Faiz ${ }^{2}$ \\ Saeed Reza Entezary ${ }^{3}$ \\ Mahnaz Narimani \\ Zamanabadi $^{4}$ \\ Mahmoud Reza Alebouyeh ${ }^{3}$ \\ 'Pain Research Center, Iran University \\ of Medical Sciences, Tehran, Iran; \\ ${ }^{2}$ Endometriosis Research Center, Iran \\ University of Medical Sciences, Tehran, \\ Iran; ${ }^{3}$ Anesthesia Department, Iran \\ University of Medical Sciences, Tehran, \\ Iran; ${ }^{4}$ Pain Fellowship, Iran University \\ of Medical Sciences, Tehran, Iran
}

Correspondence: Mahmoud Reza Alebouyeh

Faculty of Medicine, Iran University of

Medical Sciences, Tehran, Iran

Tel +98 9| 21253698

Fax +98 2I 66509059

Email dr.alebouyeh@gmail.com
Introduction: Osteoarthritis (OA) is a chronic joint disease that usually occurs in older people and leads to pain and disabilities. OA treatment ranges from drug therapy to surgery. Drug and rehabilitation therapy are preferred over surgery, and, especially, there is a tendency toward compounds causing regenerative changes in the knee joint. In the present study, the effects of platelet-rich plasma (PRP) injection and prolotherapy (PRL) were examined on the level of pain and function of the knee joint in patients with OA.

Methodology: After fulfilling the inclusion criteria and signing the informed consent form, 42 patients with knee OA were scheduled for intra-articular injection in the present randomized, double-blind, clinical trial. Following admission to the operating pain room, the condition of the patient's knee was evaluated first via the Western Ontario and McMaster Universities Osteoarthritis Index (WOMAC) and, then, ultrasound-guided knee injection was done. Accordingly, patients in the PRP therapy group received $7 \mathrm{~mL}$ PRP solution and those in the PRL group received $7 \mathrm{~mL} 25 \%$ dextrose. Using the WOMAC, levels of pain and knee function were evaluated and recorded for each patient immediately prior to the first injection as well as at 1 month (immediately prior to the second injection), 2 months (a month after the second injection), and 6 months later. Data collected were analyzed using the SPSS v.20.

Results: During the first and second months, a rapid decrease in the overall WOMAC score was observed in both groups. The overall WOMAC score increased at the sixth month, but was lower than the overall WOMAC score in the first month. Statistical analysis indicated that the overall WOMAC score significantly decreased in both groups of patients over 6 months.

Conclusion: Results of the present study suggested a significant decrease in the overall WOMAC score of patients who undergo either PRP therapy or PRL. This positive change in the overall WOMAC score led to an improvement in the quality of life of patients with knee OA shortly after the first injection. PRP injection is more effective than PRL in the treatment of knee OA.

Keywords: knee osteoarthritis, platelet-rich plasma, prolotherapy, ultrasound

\section{Introduction}

Aging affects almost all physiological processes and causes changes in body composition. Recently, a triad encompassing simultaneous destruction of bone, muscle, and adipose tissues has been identified and named the osteosarcopenic obesity syndrome. ${ }^{1-3}$ Osteopenia is the other problem that affects old people, especially in the neck of the femur or lumbar spine. Almost $80 \%$ of the American population over age 65 suffers from osteoarthritis (OA). OA is a chronic age-related joint disease that usually occurs in older people and damages articular cartilage and synovial joints. OA causes 
significant disabilities and functional limitations in daily activities of affected patients. The most important symptoms include joint pain, stiffness, swelling, and decreased range of motion. ${ }^{1-4}$ Given the high incidence of this disease and costs of medical treatments, OA can be considered an economic burden on society. Available treatments for OA can be classified into three groups: drug, nondrug/nonsurgical (eg, physical and rehabilitation therapy, occupational therapy, massage, exercise) - which are the primary line of treatment - and surgical therapies. The sequence of treatment application begins with drug therapies and ends with surgical therapies. ${ }^{5,6}$ Injectable medications that can cause regenerative changes in tissue structure, manage and alleviate $\mathrm{OA}$ symptoms, and help cope with the underlying tissue pathology are very important. This importance is due to the fact that these medicines are not only palliative but also reconstructive and preventive against replacement surgeries. Platelet-rich plasma (PRP) exists in this category. Platelets besides contributing to the process of hemostasis - play different critical roles in the body. For example, following a tissue injury, platelets attract white blood cells to the site of injury and prevent damaged cells from being infected. Moreover, platelets contain a growth factor (ie, plateletderived growth factor [PDGF]) that increases the production of stem cells. This characteristic has made platelets attractive in OA treatment. Prolotherapy (PRL) is recommended for chronic musculoskeletal and painful joint conditions, such as knee OA..$^{7-9}$ PRL involves the injection of an irritant solution into a damaged zone to encourage cell proliferation. Therefore, small amounts of an irritant solution (hypertonic dextrose injection) are injected occasionally into a damaged joint space. The exact mechanism of PRL action is not well understood yet; however, it is probably mediated by stimulation of local healing cells via inflammation induction. The efficacy of PRL and other irritant factors for the treatment of knee OA has been reported in various studies. ${ }^{10-17}$ In the present study, the effectiveness of PRP therapy and PRL are compared in reducing pain intensity and symptoms of knee OA.

\section{Methodology}

This study was undertaken as a double-blind randomized clinical trial after it was approved by the Ethics Committee of Iran University of Medical Sciences. The current study has been registered at the Clinical Trial Center (IRCT) with the code IRCT2014101810599N2. On fulfilling the inclusion criteria and signing the informed consent form, 44 patients with knee $\mathrm{OA}$ at the Rasul Akram Hospital were recruited as suitable candidates for intra-articular injection in the present randomized, double-blind clinical trial. Inclusion criteria were age range of 40-70 and stage 1 or 2 OA (based on the KellgrenLawrence [KL] scale of the Radiological Society of America); exclusion criteria were rheumatoid arthritis or hemophilia, previous history of knee surgery, drug or alcohol addiction, and use of anticoagulant or nonsteroidal anti-inflammatory drugs (NSAIDs) in the previous 7 days. The primary information, including age, gender, body mass index (BMI), stage of $\mathrm{KL}$, and X-ray scan were recorded for all patients.

Based on a previous study, we calculated the sample size. In that study, the reported percentage of satisfaction in the PRP group at 6 months was equal to $75 \%(0.75)$, whereas this percentage was $10.8 \%(0.108)$ in the normal saline injection group. When we considered the alpha as 0.05 and beta as 0.1 , with power of $95 \%$, we calculated a sample size equal to 13 in each group. We finally enrolled 21 patients in each group. ${ }^{18}$

We used a block randomization method (block size of four) for determining which patient should be assigned to which group. Randomization remained unbroken during the study.

After admission of patients to the operating theater, the patient's knee condition was evaluated on the basis of the Western Ontario and McMaster Universities Osteoarthritis Index (WOMAC). The WOMAC measures five items for pain (score range 0-20), two for stiffness (score range 0-8), and 17 for functional limitations (score range $0-68$ ). Thus, the possible WOMAC score is between 0 and $96 .{ }^{4}$

Following routine monitoring processes, such as examining blood pressure, heart rate, and an electrocardiogram, a 20-mL blood sample was drawn under sterile conditions and placed in specialized centrifuge kits for the preparation of PRP (Standard kit, Iran). Then, the blood was centrifuged for 20 minutes at a rotation speed of 3,200 rpm. The plasma was separated and recentrifuged for 5 minutes at a rotation speed of 1,500 rpm. Then, $7 \mathrm{~mL}$ of the separated plasma was prepared for intra-articular injection for patients in the PRP therapy group. Patients in the PRL group received $7 \mathrm{~mL}$ $25 \%$ dextrose.

After administration of local anesthesia and placement of a multi-frequency linear probe of (6-13 $\mathrm{MHz}$ with a depth of $6 \mathrm{~cm}$ ) an ultrasound machine (Sonosite, S-Nerve, South Korea) at the top of the patella, the intra-articular injection was administered under sterile conditions. Then, a $50 \mathrm{~mm}$ long 22-gauge needle (Visioplex needle, Vygon Company, France) was inserted into the knee joint at the upper outer quadrant of the patella under ultrasonographic guidance 
via the Inplane technique. Then, the prepared solution was injected into the knee joint; this was done with every patient, with neither the patient nor the physician aware of the content of the syringes. Patients remained under medical care for an hour and were then discharged if no complications were detected. The same procedure was repeated 1 month later for all patients. In case of postprocedural pain, paracetamol was prescribed.

Using the WOMAC, levels of pain and knee function were evaluated and recorded for each patient at specified time points - immediately prior to the first injection, 1 month later (immediately prior to the second injection), 2 months later (a month after the second injection), and 6 months later. The investigator and the data analyzer were not aware of patient allocation.

\section{Statistical analyses}

Data collected were analyzed using SPSS v. 20. We compared the data and outcome variables (physical activity, pain, stiffness, and WOMAC) between treatment groups (PRP vs PRL) and in successive sessions. Based on the nature of the variables (all are discrete variables) and number of classes, we used parametric tests for analysis of physical activity, pain, and WOMAC between groups and nonparametric tests for stiffness. With regard to physical activity, pain, and WOMAC, we first assessed the normality of data by the Kolmogorov-Smirnov test (K-S test) and determined that all of them were normally distributed - thus, we used parametric tests for analysis. Furthermore, we used mixedmodel analysis of variance (ANOVA) for analysis of physical activity, pain, and WOMAC between two groups in successive time sessions. The post hoc test was applied, and Bonferroni correction was considered for interpretation of $P$-values. For analysis of data from each treatment group in successive sessions separately, we used repeated-measures ANOVA, and all pairwise comparisons (for different time sessions) were accomplished. For comparison of two treatment groups in similar time periods, we used the Student $t$-test. For stiffness, we used nonparametric tests (Friedman test for comparison of different time sessions in each treatment groups) and Wilcoxon signed rank test for pairwise comparisons. Similar time sessions between two treatment groups were compared by Mann-Whitney $U$ test. $P$-values were considered significant at $<0.05$, and they were interpreted on the basis of Bonferroni correction. All baseline data were compared between groups by chi-square, $t$-, and Mann-Whitney $U$ tests. Normality of data were assessed by the $\mathrm{K}-\mathrm{S}$ test at first.
Table I Comparison of demographic and baseline characteristics between two groups

\begin{tabular}{llll}
\hline Patient demographic characteristics & & P-value \\
\hline Age (year) & PRP & $65.5 \pm 6.64$ & 0.53 \\
& PRL & $64.3 \pm 5.3 \mathrm{I}$ & \\
$\mathrm{BMI}\left(\mathrm{kg} / \mathrm{m}^{2}\right)$ & $\mathrm{PRP}$ & $28.6 \pm 1.8$ & 0.68 \\
& $\mathrm{PRL}$ & $28.3 \pm 1.9$ & \\
$\mathrm{KL}$ score & $\mathrm{PRP}$ & $2.47 \pm 0.5$ & 0.76 \\
& $\mathrm{PRL}$ & $2.42 \pm 0.5$ & \\
Sex (male/female) & $\mathrm{PRP}$ & $10 / 1 \mathrm{I}$ & 0.76 \\
& $\mathrm{PRL}$ & $\mathrm{II} / 10$ & \\
\hline
\end{tabular}

Abbreviations: BMI, body mass index; KL, Kellgren-Lawrence; PRL, prolotherapy; PRP, platelet-rich plasma.

\section{Results}

Forty-two patients (21 in each group) with knee OA were enrolled in the study. No significant difference was observed in demographic and baseline characteristics between the two groups (Table 1).

The severity of knee OA was assessed using the patients' WOMAC scores (ie, the sum of functional limitations, stiffness, and pain-level scores). There was no statistically significant between-group difference with regard to the WOMAC score and its subscales (including physical activity [or functional limitation], pain, and stiffness) before treatment when baseline values were collected (all $P$-values $\geq 0.73$; Table 2 ).

Mean physical activity (or functional limitation) scores recorded at baseline values are mentioned in Table 3. As we can see, in the PRL group, the physical activity score dropped from 47.8 before treatment to 19.6 in the second month and then rose to 22.8 in the sixth month. A similar pattern was seen for PRP, for which the score dropped from 47.3 before treatment to 25 in the second month to rise to 27.8 in the sixth month. In detail, all pairwise comparisons of physical activity in different time periods for both groups were statistically significant. In addition, in the mixed-model ANOVA, the

Table 2 Comparison of patient WOMAC scores and its subscales between two groups before the intervention

\begin{tabular}{llll}
\hline $\begin{array}{l}\text { Patient WOMAC scores before the } \\
\text { intervention }\end{array}$ & & P-value \\
\hline Functional limitation & PRL & $47.3 \pm 6.7$ & 0.81 \\
& PRP & $47.8 \pm 4.7$ & \\
Pain level & PRL & $14.6 \pm 1.4$ & 0.76 \\
& PRP & $14.8 \pm 1.5$ & \\
Stiffness & PRL & $5.2 \pm 1.3$ & 0.73 \\
& PRP & $5.4 \pm 1.2$ & \\
WOMAC score & PRL & $67.1 \pm 7.9$ & 0.75 \\
& PRP & $67.9 \pm 7.3$ & \\
\hline
\end{tabular}

Abbreviations: PRL, prolotherapy; PRP, platelet-rich plasma; WOMAC, Western Ontario and McMaster Universities Osteoarthritis Index. 
Table 3 Comparison of physical activity (functional limitation) between two groups in successive months

\begin{tabular}{|c|c|c|c|c|c|c|}
\hline & \multirow[b]{2}{*}{ Pretreatment } & \multirow[b]{2}{*}{$\begin{array}{l}\text { First } \\
\text { month }\end{array}$} & \multirow[b]{2}{*}{$\begin{array}{l}\text { Second } \\
\text { month }\end{array}$} & \multirow[b]{2}{*}{$\begin{array}{l}\text { Sixth } \\
\text { month }\end{array}$} & \multirow{2}{*}{$\begin{array}{l}\text { Repeated- } \\
\text { measures test } \\
\text { All }\end{array}$} & \multirow[t]{2}{*}{ Pairwise comparisons* } \\
\hline & & & & & & \\
\hline$\overline{P R L}$ & $47.3 \pm 6.7$ & $3 \mathrm{II} \pm 6.3$ & $25 \pm 5.5$ & $27.8 \pm 5.2$ & $<0.001$ & $\begin{array}{l}\text { All of } P \text {-values were } \leq 0.00 \text { I except for } \\
\text { comparison between (I vs } 6 \text { ) that was } 0.004\end{array}$ \\
\hline PRP & $47.8 \pm 4.7$ & $30.3 \pm 7.6$ & $19.6 \pm 7.2$ & $22.8 \pm 7.9$ & $<0.001$ & All $P$-values were $\leq 0.00 \mathrm{I}$ \\
\hline $\begin{array}{l}P \text {-value of between group } \\
\text { comparison in similar times }\end{array}$ & 0.81 & 0.74 & 0.009 & 0.021 & & \\
\hline \multicolumn{7}{|c|}{ Mixed-model ANOVA $P$-values } \\
\hline Group & 0.11 & & & & & \\
\hline Time & $<0.00$ I & & & & & All $P$-values were $<0.001$ \\
\hline Time*group & 0.007 & & & & & \\
\hline
\end{tabular}

Notes: *Pairwise comparisons included comparisons at different time sessions including preprocedural data (0), first-month data (I), second-month data (2), and sixth-month data (6); these were as follows: (0 vs I), (0 vs 2$),(0$ vs 6$),(I$ vs 2$),(I$ vs 6$)$, and ( 2 vs 6$)$.

Abbreviations: ANOVA, analysis of variance; PRL, prolotherapy; PRP, platelet-rich plasma.

main effect of time and interaction of time with treatment group was statistically significant, whereas the $P$-value $(0.11)$ of the main effect of the treatment group was borderline. Given the fact that a comparison of two groups in similar time sessions was statistically significant in the second and sixth months (better results for PRP; and not significant at pretreatment and in the first month), the borderline $P$-value for the treatment group in the mixed-model ANOVA could be attributed somehow to similar results of physical activity between the groups at months 0 and 1 .

The mean pain scores at baseline have been mentioned in Table 4. As we can see, in the PRL group, the pain score dropped from 14.6 before treatment to 7.1 in the second month and then rose to 8 in the sixth month. A similar pattern was seen for PRP; its score dropped from 14.8 before treatment to 5.4 in the second month and then rose to 6.2 in the sixth month. In detail, all pairwise comparisons of pain in different time periods for both groups were statistically significant. In addition, in mixed-model ANOVA, the main effect of time and interaction of time with treatment group was statistically significant, whereas the $P$-value (0.056) of the main effect of the treatment group was borderline. Given the fact that the comparison of two groups in similar time sessions was statistically significant in the second and sixth months (better results for PRP, but not in the pretreatment phase and at the first month); the borderline $P$-value for the treatment group in mixed-model ANOVA could be attributed somehow to similar results of pain between the two groups at months 0 and 1 .

The mean stiffness score from the baseline values have been mentioned in Table 5. As we can see, in PRL group, the stiffness score dropped from 5.2 before treatment to 2.6 in the second month and then rose to 3 in the sixth month. A similar pattern was seen for PRP - the stiffness score dropped from 5.4 before treatment to 2.1 in the second month

Table 4 Comparison of pain between two groups in successive months

\begin{tabular}{|c|c|c|c|c|c|c|}
\hline & \multirow[b]{2}{*}{ Pretreatment } & \multirow[b]{2}{*}{$\begin{array}{l}\text { First } \\
\text { month }\end{array}$} & \multirow[b]{2}{*}{$\begin{array}{l}\text { Second } \\
\text { month }\end{array}$} & \multirow[b]{2}{*}{$\begin{array}{l}\text { Sixth } \\
\text { month }\end{array}$} & \multirow{2}{*}{$\begin{array}{l}\text { Repeated- } \\
\text { measures test } \\
\text { All }\end{array}$} & \multirow[t]{2}{*}{ Pairwise comparisons* } \\
\hline & & & & & & \\
\hline PRL & $14.6 \pm 1.4$ & $9.5 \pm 2.3$ & $7.1 \pm 1.7$ & $8 \pm 1.6$ & $<0.001$ & $\begin{array}{l}\text { All } P \text {-values were } \leq 0.00 \text { I except for comparison } \\
\text { between (I vs } 6) \text {, which was } 0.004\end{array}$ \\
\hline PRP & $14.8 \pm 1.5$ & $9.2 \pm 2.7$ & $5.4 \pm 1.8$ & $6.2 \pm 2.1$ & $<0.001$ & $\begin{array}{l}\text { All } P \text {-values were }<0.00 I \text { except for comparison } \\
\text { between (I vs } 6) \text {, which was } 0.015 \text { and } \\
\text { comparison between ( } 2 \text { vs } 6 \text { ) that was } 0.022\end{array}$ \\
\hline $\begin{array}{l}\text { P-value of between-group } \\
\text { comparison at similar time points }\end{array}$ & 0.76 & 0.71 & 0.002 & 0.003 & & \\
\hline \multicolumn{7}{|l|}{ Mixed-model ANOVA P-values } \\
\hline Group & 0.056 & & & & & \\
\hline Time & $<0.001$ & & & & & All $P$-values were $\leq 0.00 \mathrm{I}$ \\
\hline Time*group & 0.003 & & & & & \\
\hline
\end{tabular}

Notes: *Pairwise comparisons included comparisons at different time sessions including preprocedural data (0), first-month data (I), second-month data (2), and sixth-month data (6); these were as follows: (0 vs I), (0 vs 2$)$, (0 vs 6$)$, (I vs 2$)$, (I vs 6$)$, and (2 vs 6$)$.

Abbreviations: ANOVA, analysis of variance; PRL, prolotherapy; PRP, platelet-rich plasma. 
Table 5 Comparison of stiffness scores between the two groups in successive months

\begin{tabular}{|c|c|c|c|c|c|c|}
\hline & \multirow[b]{2}{*}{ Pretreatment } & \multirow[b]{2}{*}{$\begin{array}{l}\text { First } \\
\text { month }\end{array}$} & \multirow[b]{2}{*}{$\begin{array}{l}\text { Second } \\
\text { month }\end{array}$} & \multirow[b]{2}{*}{$\begin{array}{l}\text { Sixth } \\
\text { month }\end{array}$} & \multirow{2}{*}{$\begin{array}{l}\text { Repeated- } \\
\text { measures test } \\
\text { All }\end{array}$} & \multirow[t]{2}{*}{ Pairwise comparisons* } \\
\hline & & & & & & \\
\hline PRL & $5.2 \pm 1.3$ & $3.2 \pm 1.1$ & $2.6 \pm 0.7$ & $3 \pm 0.7$ & $<0.001$ & $\begin{array}{l}\text { All } P \text {-values were }<0.00 I \text { except for comparison } \\
\text { between ( } I \text { vs } 2 \text { ), which was } 0.018 \text {, comparison } \\
\text { between (I vs } 6 \text { ), which was } 0.28 \text {, and } \\
\text { comparison between ( } 2 \text { vs } 6 \text { ), which was } 0.14\end{array}$ \\
\hline PRP & $5.4 \pm 1.2$ & $3.3 \pm 1.1$ & $2.1 \pm 0.7$ & $2.5 \pm 0.8$ & $<0.001$ & $\begin{array}{l}\text { All of } P \text {-values were } \leq 0.00 \text { I except for } \\
\text { comparison between }(2 \mathrm{vs} 6) \text {, which was } 0.07 \text { I }\end{array}$ \\
\hline $\begin{array}{l}P \text {-value of between-group } \\
\text { comparison at similar time points }\end{array}$ & 0.73 & 0.65 & 0.055 & 0.091 & & \\
\hline
\end{tabular}

Notes: *Pairwise comparisons included comparisons at different time points including of preprocedural data (0), first-month data (I), second-month data (2), and sixth-month data (6); these were as follows: (0 vs I), ( 0 vs 2$)$, ( 0 vs 6$)$, (I vs 2$)$, (I vs 6$)$, and ( 2 vs 6$)$.

Abbreviations: PRL, prolotherapy; PRP, platelet-rich plasma.

to rise to 2.5 in the sixth month. In detail, pairwise comparisons of stiffness for the PRL group at different time periods were significant except for the comparison of first versus sixth and of second versus sixth month. For PRP, pairwise comparisons at different time periods were all significant, except for the second versus the sixth month which was borderline. In addition, pairwise comparison of similar time sessions between the two groups showed that all differences were nonsignificant; however, the contrast between the two groups in the second and sixth months were quite borderline, and favored better results for PRP.

The mean WOMAC scores at baseline are reported in Table 6. In the PRL group, the WOMAC score dropped from 67.1 before treatment to 34.8 in the second month, and then rose to 38.7 in the sixth month. A similar pattern was seen for PRP, for which the score dropped from 67.9 before treatment to 27.1 in the second month and then rose to 31.4 in the sixth month. Briefly, all pairwise comparisons of WOMAC in different time periods for both groups were statistically significant. In addition, in the mixed-model ANOVA, the main effect of time and interaction of time with the treatment group was statistically significant, whereas the $P$-value (0.097) of the main effect of the treatment group was borderline. Given the fact that the comparison of the two groups at similar time sessions was statistically significant in the second and sixth months (better results for PRP, although not in the pretreatment and first month time points), the borderline $P$-value for the treatment group in the mixed-model ANOVA could be attributed somehow to similar results of WOMAC between the two groups at months 0 and 1 .

\section{Discussion}

Various noninvasive and minimally invasive methods have been used for the treatment of knee OA. The most prevalent treatments are physical and rehabilitation therapy, administration of NSAIDs and glucosamine, and, in case

Table 6 Comparison of WOMAC between two groups in successive months

\begin{tabular}{|c|c|c|c|c|c|c|}
\hline & & & & & $\begin{array}{l}\text { Repeated- } \\
\text { measures test }\end{array}$ & Pairwise comparisons* \\
\hline & Pretreatment & $\begin{array}{l}\text { First } \\
\text { month }\end{array}$ & $\begin{array}{l}\text { Second } \\
\text { month }\end{array}$ & $\begin{array}{l}\text { Sixth } \\
\text { month }\end{array}$ & All & \\
\hline PRL & $67.1 \pm 7.9$ & $43.8 \pm 8.2$ & $34.8 \pm 6.9$ & $38.7 \pm 6.6$ & $<0.001$ & $\begin{array}{l}\text { All } P \text {-values were }<0.00 \text { I except for the } \\
\text { comparison between }(2 \text { vs } 6) \text {, which was } 0.003\end{array}$ \\
\hline PRP & $67.9 \pm 7.3$ & $42.9 \pm 10.85$ & $27.1 \pm 9.1$ & $31.4 \pm 10.2$ & $<0.001$ & $\begin{array}{l}\text { All } P \text {-values were }<0.001 \text { except for the } \\
\text { comparison between (I vs } 6) \text {, which was } 0.002\end{array}$ \\
\hline $\begin{array}{l}P \text {-value of between-group } \\
\text { comparison in similar times }\end{array}$ & 0.74 & 0.77 & 0.004 & 0.009 & & \\
\hline \multicolumn{7}{|l|}{ Mix model ANOVA $P$-values } \\
\hline Group & 0.097 & & & & & \\
\hline Time & $<0.001$ & & & & & All $P$-values were $<0.001$ \\
\hline Time*group & 0.001 & & & & & \\
\hline
\end{tabular}

Notes: *Pairwise comparisons included comparisons at different time points including of preprocedural data (0), first-month data (I), second-month data (2), and sixth-month data (6); these were as follows: ( 0 vs I), (0 vs 2$),(0$ vs 6$),(I$ vs 2$),(I$ vs 6$)$, and ( 2 vs 6$)$.

Abbreviations: PRL, prolotherapy; PRP, platelet-rich plasma; WOMAC, Western Ontario and McMaster Universities Osteoarthritis Index. 
of ineffectiveness with these preliminary measures, intraarticular injection of hyaluronic acid, corticosteroid, PRP, PRL, and growth hormone as well as radiofrequency have been undertaken. ${ }^{4,12}$ Several studies have been conducted to examine the effectiveness of PRP therapy in reducing symptoms and pain associated with OA. ${ }^{15-18}$ Activated platelet results in the release of some mediators, such as growth factors and cytokines. In vivo studies showed that PRP may cause increased proliferation and differentiation of chondrocytes as well. Furthermore, PRP may have anti-inflammatory

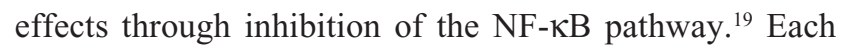
milliliter of PRP solution contains 1.5-2 million platelets, causing a 5-fold increase in platelets and growth factors. Hyperosmolar dextrose, as a PRL agent, increases levels of PDGF. PRL acts as an irritant which has been shown to be effective in the repair of connective tissue injuries. PRL is more effective than PRP therapy in the treatment of enthesitic inflammations. ${ }^{20}$

Results of the present trial indicated that PRP therapy is more effective than PRL over time. Moreover, it was shown that PRP therapy can significantly decrease pain, functional limitations, and stiffness in patients with knee OA for up to 24 weeks. In this study, the overall WOMAC score improvement was $54 \%$. Finally, $60 \%$ of the examined patients experienced a $50 \%$ improvement during a 24 -week period. In fact, the improvement process had an upward trend for up to 8 weeks after the intervention, and the maximum improvement was observed in that period; thereafter, there was a slight but nonsignificant decline in scores until Week 24. This might be due to an excessive use of the knee joint secondary to pain relief and is considered an underestimation of the results. In this study, PRP therapy was more effective than PRL in improving the quality of life of patients with knee OA.

Chang et al compared the effects of PRP and hyaluronic acid injection for knee pain and found that PRP injection is more effective for patients with damaged articular cartilage than was hyaluronic acid. Moreover, patients with mild OA responded better to PRP injection than those with severe OA. ${ }^{5}$

In a systematic review, PRL conferred a positive and significant beneficial effect in the treatment of knee OA and, in the current study, PRL had significant effectiveness as well. ${ }^{20}$ Intra-articular injection of PRP has induced a significant diminishing of degenerative articular inflammatory changes. Short-term effects of PRP in the treatment of knee OA have been examined in previous studies. These studies indicated that PRP injection is more effective than hyaluronic acid and placebo injections. Another study compared the effects of a single dose of PRP injection with corticosteroid injection on the severity of knee OA symptoms and showed that PRP reduces joint pain to a greater extent and for a longer duration. In the abovementioned study, ${ }^{16,21}$ pain and OA severity were measured via the visual analog scale, whereas a more comprehensive measure tool (ie, the WOMAC) was used in the current study. In another study, a significant difference was reported between PRP and hyaluronic acid groups of patients with WOMAC scores, where patients treated by PRP injection showed better functional scores. In a systematic review, the administration of PRP was compared against that of corticosteroids, hyaluronic acid, oral NSAIDs, and placebos. The results showed that PRP is an effective treatment for knee OA, even up to 12 months. Nevertheless, the frequent use of PRP injection increases the possibility of adverse reactions. ${ }^{21-23}$ Studies have shown that the use of growth factors can be effective in the treatment of localized cartilage defects, such as in OA. Although, there is still a need for further research in this area, it has been proven that the deficiency of the growth hormone increases the severity of articular cartilage pathology in patients with OA. ${ }^{4,8}$ According to the results of this study and previous studies, PRP injection can be useful for OA patients whose knee condition has not been improved via other therapeutic procedures, such as physiotherapy, exercise therapy, and other medications or injections.

This study had some limitations such as: lack of a control group receiving placebo; lack of morphological assessment of cartilage, soft tissue, and structures in and around the knee joint; small sample size; and limited timeframe for patient assessment. PRP therapy needs a centrifuge machine and specific kits and, thus, costs are higher than for PRL; therefore, decisions about the application of this more expensive treatment must be made properly.

\section{Conclusion}

In the present study, compared to PRL, PRP injection was more effective in reducing pain, stiffness, and functional limitations in OA patients after 2 months and for up to 6 months of follow-up. No significant side effects was observed.

\section{Author contributions}

All authors contributed toward data analysis, drafting and critically revising the paper and agree to be accountable for all aspects of the work. 


\section{Disclosure}

The authors report no conflicts of interest in this work.

\section{References}

1. Lane NE, Brandt K, Hawker G, et al. OARSI-FDA initiative: defining the disease state of osteoarthritis. Osteoarthritis Cartilage. 2011;19(5): 478-482.

2. Suri P, Morgenroth DC, Hunter DJ. Epidemiology of osteoarthritis and associated comorbidities. PM R. 2012;4(5 Suppl):S10-S19.

3. JafariNasabian P, Inglis JE, Reilly W, Kelly OJ, Ilich JZ. Aging human body: changes in bone, muscle and body fat with consequent changes in nutrient intake. J Endocrinol. 2017;234(1):R37-R51.

4. Rahimzadeh P, Imani F, Faiz SH, et al. Adding intra-articular growth hormone to platelet rich plasma under ultrasound guidance in knee osteoarthritis: a comparative double-blind clinical trial. Anesth Pain Med. 2016;6(6):e41719.

5. Chang KV, Hung CY, Aliwarga F, Wang TG, Han DS, Chen WS. Comparative effectiveness of platelet-rich plasma injections for treating knee joint cartilage degenerative pathology: a systematic review and meta-analysis. Arch Phys Med Rehabil. 2014;95(3):562-575.

6. Schianchi PM, Sluijter ME, Balogh SE. The treatment of joint pain with intra-articular pulsed radiofrequency. Anesth Pain Med. 2013;3(2): 250-255.

7. Krstičević M, Jerić M, Došenović S, Jeličić Kadić A, Puljak L. Proliferative injection therapy for osteoarthritis: a systematic review. Int Orthop. 2017;41(4):671-679.

8. Rahimzadeh P, Imani F, Faiz SH, Entezary SR, Nasiri AA, Ziaeefard M. Investigation the efficacy of intra-articular prolotherapy with erythropoietin and dextrose and intra-articular pulsed radiofrequency on pain level reduction and range of motion improvement in primary osteoarthritis of knee. J Res Med Sci. 2014;19(8):696-702.

9. Reeves KD, Sit RW, Rabago DP. Dextrose prolotherapy: a narrative review of basic science, clinical research, and best treatment recommendations. Phys Med Rehabil Clin N Am. 2016;27(4):783-823.

10. Smelter E, Hochberg MC. New treatments for osteoarthritis. Curr Opin Rheumatol. 2013;25(3):310-316.

11. Howell R, Kumar NS, Patel N, Tom J. Degenerative meniscus: pathogenesis, diagnosis, and treatment options. World J Orthp. 2014;5(5): 597-602.
12. Kon E, Filardo G, Drobnic M, et al. Non-surgical management of early knee osteoarthritis. Knee Surg Sports Traumatol Arthrosc. 2012;20(3): 436-449.

13. Pietrzak WS, Eppley BL. Platelet rich plasma: biology and new technology. J Craniofac Surg. 2005;16(6):1043-1054.

14. Werner S, Grose R. Regulation of wound healing by growth factors and cytokines. Physiol Rev. 2003;83(3):835-870.

15. Sampson S, Gerhardt M, Mandelbaum B. Platelet rich plasma injection grafts for musculoskeletal injuries: a review. Curr Rev Musculoskelet Med. 2008;1(3-4):165-174.

16. Kim SB, Kwon DR, Kwak H, et al. Additive effects of intra-articular injection of growth hormone and hyaluronic acid in rabbit model of collagenase-induced osteoarthritis. J Korean Med Sci. 2010;25(5): 776-780.

17. Gobbi A, Karnatzikos G, Mahajan V, Malchira S. Platelet-rich plasma treatment in symptomatic patients with knee osteoarthritis: preliminary results in a group of active patients. Sports Health. 2012;4(2):162-172.

18. Patel S, Dhillon MS, Aggarwal S, Marwaha N, Jain A. Treatment with platelet-rich plasma is more effective than placebo for knee osteoarthritis: a prospective, double-blind, randomized trial. Am J Sports Med. 2013; 41(2):356-364.

19. Lai LP, Stitik TP, Foye PM, Georgy JS, Patibanda V, Chen B. Use of platelet-rich plasma in intra-articular knee injections for osteoarthritis: a systematic review. PM R. 2015;7(6):637-648.

20. Sit RW, Chung VC, Reeves KD, et al. Erratum: hypertonic dextrose injections (prolotherapy) in the treatment of symptomatic knee osteoarthritis: a systematic review and meta-analysis. Sci Rep. 2017;7:45879.

21. Kanchanatawan W, Arirachakaran A, Chaijenkij K, et al. Short-term outcomes of platelet-rich plasma injection for treatment of osteoarthritis of the knee. Knee Surg Sports Traumatol Arthrosc. 2016;24(5): $1665-1677$.

22. Lippross S, Moeller B, Haas H, et al. Intraarticular injection of plateletrich plasma reduces inflammation in a pig model of rheumatoid arthritis of the knee joint. Arthritis Rheum. 2011;63(11):3344-3353.

23. Campbell KA, Saltzman BM, Mascarenhas R, et al. Does intra-articular platelet-rich plasma injection provide clinically superior outcomes compared with other therapies in the treatment of knee osteoarthritis? A systematic review of overlapping meta-analyses. Arthroscopy. 2015; 31(11):2213-2221.
Clinical Interventions in Aging

\section{Publish your work in this journal}

Clinical Interventions in Aging is an international, peer-reviewed journal focusing on evidence-based reports on the value or lack thereof of treatments intended to prevent or delay the onset of maladaptive correlates of aging in human beings. This journal is indexed on PubMed Central, MedLine,

\section{Dovepress}

CAS, Scopus and the Elsevier Bibliographic databases. The manuscript management system is completely online and includes a very quick and fair peer-review system, which is all easy to use. Visit http://www.dovepress. com/testimonials.php to read real quotes from published authors. 